\title{
Supporting health-related parenting: A scoping review of programs assisted by the Internet and related technologies
}

\author{
Apoiando a parentalidade relacionada com a saúde: uma revisão \\ abrangente dos programas assistidos pela Internet e tecnologias \\ relacionadas
}

\author{
Luísa BARROS ${ }^{1}$ \\ Klara GREFFIN ${ }^{1}$
}

\begin{abstract}
eHealth interventions have been proposed as a possible solution to overcome major obstacles associated with low adherence rates, low accessibility, and high costs of parenting programs. Due to the number and variety of interventions found in the literature, this study aimed to conduct a scoping review of parenting interventions directed at supporting parents in promoting their child's health and carrying out disease-related tasks. The scoping review identified 119 technology-based programs directed both at universal, preventive objectives and at the management and adaptation to chronic or severe acute health conditions. Several different web-based applications have been creatively used in healthrelated parenting interventions. Most programs use evidence-based psychological methodologies to promote parental self-management, build specific parenting skills, and provide customized feedback and social support. Further studies are needed to assess the contribution of the Internet and mobile applications to enhance the effectiveness of health-related parenting interventions and the dissemination of empirically validated programs.
\end{abstract}

Keywords: Health; Information technology; Parenting; Programs; Review.

\section{Resumo}

Intervenções de eSaúde foram propostas para superar obstáculos relacionados com baixas taxas de adesão, baixa acessibilidade e custos elevados. Devido à diversidade de intervenções existentes, este estudo objetivou conduzir uma revisão abrangente das intervenções parentais para apoiar os pais nas tarefas relacionadas com a saúde e a doença dos filhos. A revisão abrangente encontrou 119 programas baseados em tecnologia, tanto direcionados para objetivos universais e preventivos, quanto para a gestão e adaptação a condições de saúde graves, crônicas ou agudas. Uma diversidade de aplicações foi utilizada de forma criativa em intervenções parentais. A maioria dos programas utiliza metodologias psicológicas baseadas em evidências para promover a autogestão, treinar habilidades parentais específicas e oferecer feedback personalizado e apoio social. São necessárias mais investigações para avaliar a contribuição da Internet e das aplicações móveis para aumentar a eficácia das intervenções parentais relacionadas com a saúde e a divulgação de programas empiricamente validados.

Palavras-chave: Saúde; Tecnologia da informação; Responsabilidade parental; Programas; Revisão.

${ }^{1}$ Universidade de Lisboa, Faculdade de Psicologia, Centro de Investigação em Ciências Psicológicas. Alameda da Universidade, 1649013, Lisboa, Portugal. Correspondência para/Correspondence to: L. BARROS. E-mail: <lbarros@psicologia.ulisboa.pt>. 
The need to support parents in their educational tasks has been recognized as a public health objective (Hoghughi, 1998). Several parenting interventions have been developed and empirically validated (Kohl, Schurer, \& Bellamy, 2009). Most of these interventions are delivered individually or in small groups and use a face-toface format. Since the turn of the century, several parenting programs have been proposed using eHealth interventions to help overcome major obstacles associated with low adherence rates, problems with accessibility, and high costs of parenting interventions (Pagliari et al., 2005).

A recent review on technology-assisted interventions for parents of young children (Hall \& Bierman, 2015) identified a wide range of high-level feasibility programs using diversified technology applications. These programs include mostly educational materials and behavioral strategies to promote positive parenting, as well as a variety of objectives, including universal programs and indicated interventions targeting developmental and behavioral problems. Mixed findings about the acceptability, parent engagement, and impact of these programs have been reported. Another review about family-focused mental health interventions found good evidence for the effectiveness of parent training using evidencebased parenting strategies through technologybased interventions (MacDonell \& Prinz, 2016).

Beyond the more global parenting and educational tasks, parents face important challenges associated with the promotion of their child's health, the prevention of common health problems, the treatment or adaptation to chronic child health conditions, and the use of health care services. Parents often use the Internet to search for information about their children's health or for a specific child's condition (Whyte \& Hunter, 2008), and they are more likely than non-parents to use the Internet to seek online health and medical information (Fox, 2005). Knapp et al. (2011) found that low-income parents of children with special health care needs use the Internet as a source of information about their children's health. Still, those with lower levels of education were less confident in using the Internet for this purpose and had more difficulty in determining the quality of information.

Eysenbach (2001, p.1) defined eHealth as "health services and information delivered or enhanced through the Internet and related technologies", including any applications of intervention technologies to promote or modify health behaviours. These eHealth interventions use a variety of technologies such as the Internet, cell phones, personal digital assistant, compact disk, pagers, computer games, and virtual reality (Palermo, Wilson, Peters, Lewandowski, \& Somhegyi, 2009).

eHealth and telemedicine interventions have been proposed as a solution to overcome major barriers in health care delivery (Field \& Grigsby, 2002), such as geographic distance and accessibility, high costs, shortage of specialized professionals, and the stigma associated with mental illness (MacDonell \& Prinz, 2016). This rising tendency results from the belief that technology can contribute to improve the quality of intervention delivery and increase participants' engagement (Jones, 2014). Some authors advocate the use of new technologies to enhance the dissemination of evidence-based interventions by increasing accessibility and reducing costs (Jones, 2014). As they allow a more widespread dissemination of rigorous information and access to effective interventions, technologies can play a significant role in empowering parents (Madge \& O'Connor, 2006).

There are several eHealth interventions aiming at the support of health-related parenting directed to parents of healthy or chronically ill children and adolescents or involving parents and children. The target populations and specific health conditions, as well as the technologies used and formats, are greatly diversified, and we still lack a portrait of this field of intervention as a whole. Due to the number and variety of interventions 
found in the literature, this study aims to conduct a scoping review of parenting interventions directed at supporting parents in their child's health and disease related parenting tasks.

As recommended for exploratory scoping reviews (Armstrong, Hall, Doyle, \& Waters, 2011), a broad definition of the research target was used, considering both universal programs directed to health promotion and prevention as well as indicated programs directed to acute or chronic health conditions designed for parents of children from birth to adolescence (0-18 years old).

The following research questions were defined: What is known from the existing literature about technology-assisted parenting interventions directed to support parents in their roles in health promotion and in caring for children with acute or chronic illness? What health behaviours and what medical conditions do these programs target? What are the technologies used and for what purposes are they used? What are the main psychological methodologies used in these programs?

\section{Methods}

A scoping review can be used to map rapidly the key concepts underpinning a research area and the main sources or types of evidence available (Mays, Roberts, \& Popay, 2001). The present study follows the framework proposed by Arksey and Malley (2005) and uses the scoping review process to search existing programs. This framework consists of the following main stages: design and search for relevant studies, selection of studies, charting the data, and finally the collation, summarization, and report of the results. As typically recommended for scoping reviews, the appraisal and inclusion of evidence is not limited by the methodological quality of that evidence (Levac, Colquhoun, \& O'Brien, 2010), and the review was not aimed to select studies according to their methodological or evidence quality.

Comprehensive literature searches using the medical and psychological bibliographic databases
PsycINFO and PubMed/MedLine were undertaken; in addition, supplementary manual searches in relevant journals were also made. Considering the period during which eHealth interventions were developed (Pagliari et al., 2005), studies from January 2000 to the present date (February 2017) were included. Search terms included parent*intervention OR parent* program OR parent* training AND child* OR pediatric AND health OR health promotion OR prevention OR chronic condition OR chronic illness OR chronic disease AND web-supported OR internet OR internet-based OR technology* OR online OR app OR smartphone OR telehealth OR web-based. The wildcard character $\left({ }^{*}\right)$ was used to ensure that variations of each keyword would be retrieved. Search limiters were applied to exclude studies with samples of parents of children older than 18 years old and studies written in a language other than English.

Since the focus of the present study was to identify the diversity and scope of the programs, when multiple articles from the same research group and pertaining to the same program were found, the article that more thoroughly described the program was selected. The inclusion criteria were as follows: (a) parenting interventions directed at supporting parents in promoting the health of their children, in the adaptation to a chronic or long-term health condition in a child (e.g., accident prevention, asthma, traumatic brain injury), or in their relationship with healthcare services; (b) interventions that use any type of technology support: online or web-based interventions, interventions that use the Internet to communicate with parents, interventions that use smartphone applications or other online applications (apps); (c) intervention programs entirely based on the use of Internet, web-based technologies, or apps which used these technologies as an adjunct to other types of face-to-face individual or group interventions.

Some articles were excluded for the following reasons: (a) they addressed interventions for parents who have a health condition themselves (e.g., parents with depression or bipolar disorder); (b) they focused on interventions for parents of children with behavioral, developmental, or mental 
health problems (e.g., autism or anxiety disorders); (c) they did not provided enough information about the program; (d) they addressed programs in which parents had more limited participation since they were directed to the organization of services, or they provided alternative forms of medical consultations (e.g., telehealth for long-distance medical consultations).

The two authors independently evaluated each study using the inclusion and exclusion criteria described above. They recorded their evaluation by labeling the articles as Relevant (R), Irrelevant (I), Doubtful (D), or Repeated Program (RP). Next, full-text articles were reviewed and crosschecked. In case of disagreement, a consensus was reached through discussions between the two authors.

Results were analysed using a charting approach considering predefined criteria: (a) health issues and conditions; (b) types of technologies used and their use as sole intervention or to complement face-to-face interventions; (c) participants' involvement (only parent; parent and child); (d) psychological methodologies involved.

\section{Results}

Figure 1 shows the flowchart of the selection of articles and interventions. The search conducted yielded 10989 peer-reviewed articles for further screening, and 143 studies met the criteria. Finally, 119 different interventions were identified and analyzed.

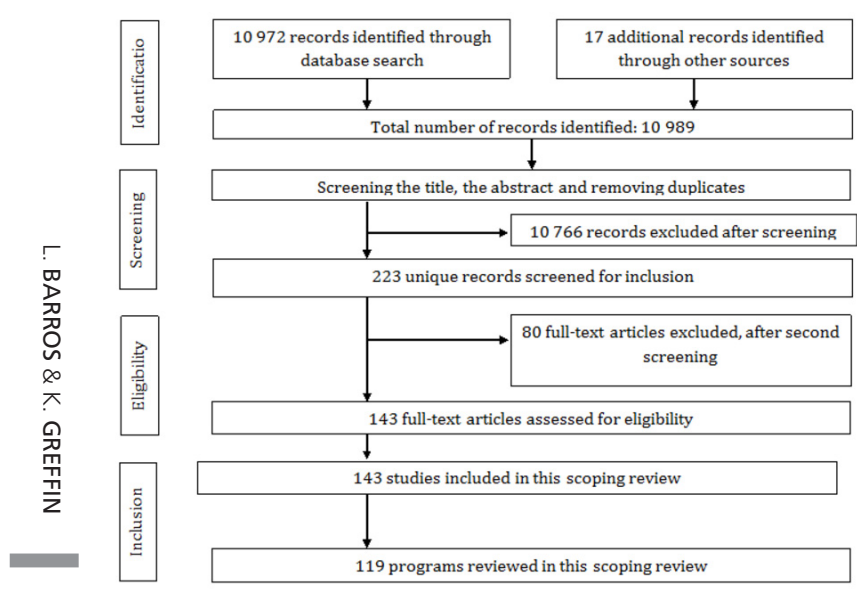

334

Figure 1. Flowchart of the selection of articles and interventions.

\section{Health-related targets}

The large number of different programs confirms that eHealth interventions are a growing strategy in the domain of health related parenting interventions in the domain of health-related parenting interventions (Table 1). The diversity of target populations and aims were organized into two large groups. The first one included universal interventions directed at supporting parents, from the child's birth to the transition to college, in their tasks to promote healthy behaviours and attitudes or to identify and solve common health problems. As expected, the most frequently identified programs were those directed at promoting healthy eating habits or at obesity prevention.

The second group included all programs directed to specific chronic conditions or severe acute diseases or procedures. Several interventions were directed to the most common pediatric chronic conditions, while others targeted rare conditions, for which it is more difficult to obtain information and support. Again, overweight was the the most frequently targeted condition, followed by asthma, allergies, and respiratory diseases, corresponding to common and difficult to manage chronic childhood conditions. However, some rare problems are very frequently addressed (sequels of traumatic brain injury), while more common problems (e.g., enuresis) were not at all or rarely (e.g., sleep problems) addressed.

\section{Participants' involvement}

The conducted scoping review identified interventions solely directed towards parents (Merkel \& Wright, 2012; Stark et al., 2015) and child or youth-centered interventions involving parents as an adjunct. In this case, the role of the parent can be parallel to the one of the child, such as in one chronic pain intervention (Palermo et al., 2009), in which parents and children participate in a web-based program which includes specific modules directed to each one. Some programs are directed to parents and children together and 
aim to stimulate specific interactions or family behavior patterns (Delamater et al., 2013; Fang \& Schinke, 2013). Yet, others such as that proposed by Baranowski et al. (2003) are child or adolescentcentered programs, often in a face-to-face or group format, and provide information or coaching to parents through online complementary modules. Most interventions that target adolescent health problems have an important component directed to them, and the parents play an adjunctive role, while most programs for younger children-related issues are centered on parents alone.

\section{Technologies used}

The conducted scoping review showed the creative use of a wide range of technological applications. In this section, the main characteristics of each technology are described and examples are provided. However, many of the programs reviewed used a combination of different technologies to ensure a more comprehensive and integrated intervention. The major technologies involved in each program are described below.

Table 1

Health issues and chronic conditions targeted by the programs

\begin{tabular}{|c|c|c|c|}
\hline Prevention/promotion & Number of studies & Conditions & Number of studies \\
\hline $\begin{array}{l}\text { Obesity and overweight prevention } \\
\text { (eating and/or activity) }\end{array}$ & 20 & Obesity and overweight treatment & 18 \\
\hline Vaccination & 8 & Cancer & 7 \\
\hline Child safety & 4 & Traumatic brain injury & 6 \\
\hline Alcohol \& substance use & 3 & Diabetes & 5 \\
\hline Use of health services & 3 & Chronic pain & 3 \\
\hline Breastfeeding & 1 & Chronic kidney disease & 2 \\
\hline Informed consent & 1 & Cystic fibrosis & 2 \\
\hline Oral health & 1 & Extreme preterm infants & 2 \\
\hline Prevention of eating disorders & 1 & Inflammatory bowel disease & 2 \\
\hline \multirow[t]{9}{*}{ Sexual and reproductive health } & 1 & Burned children & 1 \\
\hline & & Encopresis & 1 \\
\hline & & Eczema & 1 \\
\hline & & Infant cranial abnormalities & 1 \\
\hline & & Neurofibromatosis type 1 & 1 \\
\hline & & Pediatric acute care & 1 \\
\hline & & Sleep management & 1 \\
\hline & & Surgery & 1 \\
\hline & & Trauma & 1 \\
\hline Total & 54 & Total & 66 \\
\hline
\end{tabular}

\section{Web-based interactive and structured programs}

The majority of the programs identified ( $\mathrm{N}$ $=61$ ) were structured self-guided interventions operated through a website. They usually included a sequence of online sessions, provided at regularly scheduled intervals (e.g., once a week) and used several components such as information, quizzes, suggestions of activities, or coaching and behavioral skills training. Task completion is followed by individually tailored feedback on progress, incentives, and reinforcement or suggestions to overcome difficulties. Most online programs are theory-driven interventions, and replicate face-to-face programs that have been previously empirically validated (Clarke, Calam, 
Morawska, \& Sanders, 2013; Doherty, Calam, \& Sanders, 2013). In some cases, the technologymediated programs are delivered combined with face-to-face sessions (e.g., Maddison et al., 2014).

\section{Web-based platforms for information delivery}

The second largest group of interventions ( $\mathrm{N}$ $=18$ ) included easy-to-use platforms with a large variety of information that parents can consult whenever they wish to learn the most relevant information on their child's health or illness. This method of disseminating information can be more appealing, flexible, and suitable to the needs and preferences of diverse populations, since they include videos and audio clips, animations, illustrations, pictures, and text materials.

These programs often include interactive elements so that parents can receive answers tailored to their doubts or worries (Starling et al., 2014). A particular adaptation of this technology (Carlson Gielen et al., 2007) involved inviting parents visiting an emergency service to use a computer kiosk containing a website on child safety measures and to fill in a questionnaire. The participant parents received a printed tailored report with suggestions to change their child's safety behaviors.

\section{Online discussion chat rooms and forums}

Nine interventions involved computer or mobile phone-mediated support groups, allowing parents to communicate, discuss, and share issues related to their children's health conditions or illnesses by connecting with other parents facing similar challenges in a secure environment. Several technologies may be involved, such as email (Bragadóttir, 2008), Facebook parent group (Campbell et al., 2016; Gruver et al., 2016), chat rooms, forums, blogs, or discussion boards (Ewing et al., 2009; Martin et al., 2016). The common a psychologist or a health professional that monitors the adequacy of messages and information and provides additional information or feedback when appropriate.

\section{Portable applications}

The use of mobile phone or tablet applications was tested in eight interventions designed to help parents monitor and change their child's health related behavior. These applications may include a variety of formats allowing parents to receive individually tailored short informational or motivational messages providing feedback on progress or outcomes (Curtis, Lahiri, \& Brown, 2015). These applications may have a feature that allows parents to enter information about specific occurrences or events (e.g., eating behaviors and physical activity) and children's clinical parameters or participation in scheduled activities. Some interventions include parental goal setting, monitoring, and feedback (Nezami, Lytle, \& Tate, 2016).

\section{Web-based decision-making aids}

A number of programs and applications $(\mathrm{N}=$ 7) have been developed to facilitate decisions about the child's health using platforms or applications that provide tailored information and decision aids designed to help parents understand their options and potential outcomes and consider the possible benefits and harms of their choices. These may include probabilistic information in easy to understand presentations, information about the potential outcomes of each choice, and exercises to clarify values and guide parents through their thinking process (O'Connor et al., 2009). For instance, parents receive preliminary information and fill in an individual questionnaire and are then guided through their decision making process concerning immunizations (Seeber et al., 2017) or are coached on how to monitor and control chronic asthma through an adaptation of previously prescribed measures (Nkoy et al., 2012). 


\section{Videoconferencing with therapist or a specialized healthcare provider}

Five programs used technologies such as videoconferences or video telephone to make scheduled individual or group calls, allowing synchronous communication with parents who have difficulties in attending face-to-face consultations. Specialized healthcare professionals provide specific education, counseling, and monitoring concerning difficult parenting tasks or problems. Harris, Freeman, and Duke (2015), for example, used a structured parent and adolescent training program through scheduled Skype calls with a psychologist to improve diabetes outcome in youth.

\section{Individualized programmed short message service}

Individually tailored messages were used alone or as a component in more complex interventions $(N=5)$. Their common feature was message scheduling and customized contents, which was used to support parents' efforts to change their role in supporting their child/ adolescent's progress. Simple messages are used mostly to remind and motivate parents (e.g., to improve vaccination rates) (Domek et al., 2016). A creative technology, the Talking-Card, was proposed by Cowden et al. (2015), through which, after the medical consultation, parents received a card containing a chip with recorded customized instructions by the pediatrician.

\section{Telephone calls with automated interactive voice}

Four interventions used Interactive Voice Response (IVR) technologies to guide parents at home through interactive, speech-based discussions to gather information about the treatment and the child's progress or to reinforce recommendations and treatments. IVR systems are particularly well suited for use by vulnerable populations because they only require users to have access to a telephone. They use synthetic speech and spoken responses (Adams et al., 2014). The used informatics system allows personalization of the calls, for instance, by identifying the child by their name and mentioning specific aspects of the child's process (e.g., medication).

\section{Videogames}

Although most eHealth videogames are directed at children, two examples directed at parents were found. They involved games addressing parent-child/adolescent interactions, allowing parents to improve communication by teaching them skills to talk about sexuality with their adolescent children (Bayley \& Brown, 2015) or to lead their child to comply with a specific health behavior (Beltran et al., 2012).

\section{Psychological methods involved}

As mentioned before, the use of technologies in parenting programs results mainly from the belief that they could be more accessible, acceptable, and easy to disseminate among hard-to-reach populations, and that they have lower costeffectiveness ratios. Therefore, they are mainly grounded on behavioral evidence-based methods. In some of the articles reviewed, the use of a theory-driven approach is clearly stated and detailed, whether in others it was more implicit. It is important to investigate how technology mediated interventions can successfully replicate face-to-face interventions and also how these technologies can enhance the applicability and efficacy of other methods or even develop new methods of intervention.

According to the organization proposed by Kahana, Drotar, and Frazier (2008), it can be observed that most programs included informational or educational strategies. These interventions are aimed at promoting parental competence and 
autonomy, adherence to preventive practices or medication regimens, to offer the cognitive requisites for parents to be able to set health goals for their children, take informed decisions, and monitor their child's health progress.

However, most programs reviewed are not limited to information and education and aim directly to change parenting behaviour through the acquisition of effective self-management skills, more effective coping strategies, or positive parenting strategies (Fidika et al., 2015). A large number of programs addressed specific components outlined by self-regulation and self-efficacy theories (i.e., intrinsic goal setting, and self-monitoring) by providing information, guided feedback, and social support (Curtis et al., 2015). Changing outcome expectations, perception of barriers to effective behavior change, and the ability to restructure the child's environment are important parenting competencies targeted in several programs (Nezami et al., 2016). Promoting parental motivation to implement a healthier lifestyle for their children, to change specific health behaviors, to increase adherence to preventive or treatment measures, and promoting parental self-efficacy are explicit key dimensions in most of these programs (e.g. Armbrust et al., 2015; Chen, Weiss, Heyman, Cooper, \& Lustig, 2011; Merkel \& Wright, 2012).

Direct instructions reinforced by coaching or modelling were used to help parents develop or adopt positive parenting strategies (reflective listening, reinforcing, relaxation training) related to healthy life-styles or to the adherence to treatment. Antonini, Raj, Oberjohn, and Wade (2012) developed a training program for parents of brain injured children combining modelling with a parental role-play of their newly acquired skills, which was recorded and sent to the therapist so that direct feedback could be provided.

Many of the interventions included a component of self-monitoring or monitoring of the child's behaviours and symptoms as a critical element to promote effective parental self-management (Nkoy et al., 2012). Portable devices, such as a pedometer (Delamater et al., 2013), can facilitate the monitoring of the child's physical activity.

Several programs using parental selfmonitoring also included some type of customized feedback to help parents recognize their progress and reinforce their behaviour change efforts (Cook et al., 2015; Delisle et al., 2015; Militello, Melnyk, Hekler, Small, \& Jacobson, 2016). Self-monitoring with timely feedback can improve motivation and maintain adherence to behaviour modification programs by reinforcing involvement efforts and correcting errors and failures. Interventions targeting preventive parenting behaviors were based on giving feedback to parents to change their perception of social norms and increase their awareness of their child's behavior towards normative guidelines and possible consequences of these behaviors. A program aiming at controlling adolescent alcohol consumption (Brown, Dunn, \& Budney, 2014) is a good example of this concept. Fidika et al. (2015) proposed an intervention for parents of children with cystic fibrosis, in which a therapist gave individualized weekly feedback to parents to coach them toward the adoption of more effective coping strategies.

Several interventions provide social support for parents that may feel more isolated, aiming to help them adapt to difficult transitions or chronic conditions. Receiving adequate social support can help decrease emotional disturbance, facilitate parental self-efficacy (Stewart, Letourneau, Masuda, Anderson, \& McGhan, 2011), and enhance the quality of life of families (Bensink et al., 2007). The possibility of synchronous communication with other parents that are experiencing similar problems through videoconferencing or establishing communication at their own pace using blogs or Facebook groups can make a difference for more isolated and vulnerable parents (Bragadóttir, 2008).

When targeting specific chronic conditions, several interventions use Cognitive-Behaviour Therapy (CBT) principles and techniques and integrate cognitive and behavioural evidence-based methods to encourage parents to change their maladaptive 
beliefs about their child's health conditions, control anxiety, and increase perceived control. These programs aim to encourage parents to use more positive and effective educational practices and to teach them how to coach their chronically ill child to control pain or other symptoms. Several family-based CBT programs to control chronic pain, which include multiple elements, such as relaxation training, activity pacing, problem solving, and distraction techniques (Nieto et al., 2015; Palermo et al., 2016, 2009; Stinson et al., 2010) have offered preliminary evidence Other examples are the Triple-P programs for parents of children with asthma (Clarke et al., 2013) and type1 diabetes (Doherty et al., 2013). These programs, derived from the Triple P Positive Parenting Program to prevent behavioural and emotional child problems, are based on the social learning theory and are aimed at increasing parental self-efficacy, through training on disease management strategies. An innovative approach uses CBT with adolescents with gastrointestinal functional disorders, emphasizing the use of exposure treatment to practice experiencing symptoms in difficult situations, to reduce avoidance behaviors and fear of symptoms (Bonnert et al., 2014). In this case, the role of the parents in helping and reinforcing the exposure component seems critical to the success of the intervention (Levy et al., 2010).

\section{Discussion}

This scoping review resulted in the identification of a variety of technology-based interventions directed at supporting health-related parenting and aimed both at universal preventive programs and the management and adaptation to chronic or severe acute health conditions. Many of these interventions replicate face-toface empirically validated or evidence-based programs and a large number are theory-driven interventions. These programs are in different stages of implementation and validation, which was not assessed in this review. Previous metaanalysis or systematic reviews (Cushing \& Steele,
2010; Hall \& Bierman, 2015; MacDonell \& Prinz, 2016) have already contributed to evaluate the effectiveness of technology-based programs targeting specific conditions, but more research is necessary. An optimistic perspective arises from the meta-analysis carried out by Wantland, Portillo, Holzemer, Slaughter, \& McGhee (2004), which found that the use of web-based interventions for adults with chronic conditions showed larger effect sizes than the face-to-face programs in terms of the acquisition of knowledge and behaviour change.

One of the interesting questions that remains to be answered is the extent to which these programs represent an improvement of the effectiveness of psychological intervention methods. One may suggest that accessing complex information, being exposed to modelling, selfmonitoring with appropriate feedback, guiding through decision-making processes, and social support provision are all important methodologies that can be significantly enhanced through the use of more sophisticated, individualized, and portable technologies (Jones et al., 2013). Interactive systems allow the input of more individual personal information and a better tailoring of the program to the individual user (Ritterband \& Palermo, 2009).

Additionally, it is important to investigate the extent to which these technology-based interventions contribute to a more generalized and easier access of parents with lower levels of technological literacy. Low-income parents have less competence to navigate the World-Wide Web and to distinguish between high and low quality information (Knapp et al., 2011). However, some programs directly targeted populations that are more vulnerable with positive results (Horodynski, Silk, Hsieh, Hoffman, \& Robson, 2015).

The results of this scoping review should be considered in light of its limitations. Firstly, only PubMed and Psyclnfo databases were searched, and although supplementary manual searches were made, it is possible that some relevant 
programs were not retrieved and therefore were not reviewed. Additionally, only English language papers published after 2000 were considered. Secondly, although the authors tried to analyse the main features of the programs, due to journals restrictions on text length it was impossible to analyse all of the relevant details in these programs or to highlight the specific innovative contributions of many studies.

The scoping review approach proved adequate to the level of development of this broad field of health-related parenting interventions assisted by the Internet and other technologies, allowing us to highlight the major trends in terms of targets, technologies, and psychological methodologies used.

It can be concluded that the technologybased parenting interventions are becoming much more widespread (the number of papers published after 2010 is four-and-a-half times higher than the number of articles published between 2000 and 2009), congregating the creativity of many different professionals, such as physicians, nurses, psychologists, engineers, computer technicians, and multimedia designers. We hope this review can help highlight the specific contribution of psychological methodologies to promote behaviour change and psychological well-being in the field of healthrelated parenting programs and reinforce the need to design, implement, and disseminate empirically validated technology-based interventions that can support parents in their demanding health-related tasks.

\section{Contributors}

L. BARROS and K. GREFFIN contributed to the conception and design of the study, data analysis and final writing.

\section{References}

Adams, W. G., Phillips, B. D., Bacic, J. D., Walsh, K. E., Shanahan, C. W., \& Paasche-Orlow, M. K. (2014). primary care visits: A randomized trial. Pediatrics, 134(3), e691-e699. https://doi.org/10.1542/ peds.2013-3759

Antonini, T. N., Raj, S. P., Oberjohn, K. S., \& Wade, S. L. (2012). An online positive parenting skills programme for paediatric traumatic brain injury: Feasibility and parental satisfaction. Journal of Telemedicine and Telecare, 18(6), 333-338. https://doi.org/10.1258/ jtt.2012.120404

Arksey, H., \& Malley, L. O. (2005). Scoping studies: Towards a methodological framework. The International Journal of Social Research Methodology, 8(1), 19-32. https://doi.org/10.1080/1364557032000119616

Armbrust, W., Bos, J. J. F. J., Cappon, J., van Rossum, M. A. J. J., Sauer, P. J. J., Wulffraat, N., ... Lelieveld, O. T. H. M. (2015). Design and acceptance of Rheumates@ Work, a combined internet-based and in person instruction model, an interactive, educational, and cognitive behavioral program for children with juvenile idiopathic arthritis. Pediatric Rheumatology Online Journal, 13, 31. https://doi.org/10.1186/s12969015-0029-5

Armstrong, R., Hall, B. J., Doyle, J., \& Waters, E. (2011). Cochrane update "scoping the scope" of a cochrane review. Journal of Public Health, 33(1), 147-150.

Baranowski, T., Baranowski, J. C., Cullen, K. W., Thompson, D. I., Nicklas, T., Zakeri, I. F., \& Rochon, J. (2003). The Fun, Food, and Fitness Project (FFFP): The Baylor GEMS pilot study. Ethnicity \& Disease, 13(Suppl.1), 30-39.

Bayley, J. E., \& Brown, K. E. (2015). Translating group programmes into online formats: Establishing the acceptability of a parents' sex and relationships communication serious game. BMC Public Health, 15(1), 1225. https://doi.org/10.1186/s12889-0152545-0

Beltran, A., O'Connor, T., Hughes, S., Baranowski, J., Nicklas, T. A., Thompson, D., \& Baranowski, T. (2012). Alpha test of a videogame to increase children's vegetable consumption. Games for Health Journal, 1(3), 219-221. https://doi.org/10.1089/ g4h.2011.0027

Bensink, M., Wootton, R., Irving, H., Hallahan, A., Theodoros, D., Russell, T., ... Barnett, A. G. (2007). Investigating the cost-effectiveness of videotelephone based support for newly diagnosed paediatric oncology patients and their families: Design of a randomised controlled trial. BMC Health Services Research, 7(38), 1-8. https://doi.org/10.1186/14726963-7-38

Bonnert, M., Ljótsson, B., Hedman, E., Andersson, J., Arnell, H., Benninga, M. A., ... Serlachius, E. (2014). Internet-delivered cognitive behavior therapy for adolescents with functional gastrointestinal disorders: 
An open trial. Internet Interventions, 1(3), 141-148. https://doi.org/10.1016/j.invent.2014.07.002

Bragadóttir, H. (2008). Computer-mediated support group intervention. Journal of Nursing Scholarship, 40(1), 32-38.

Brown, P. C., Dunn, M. E., \& Budney, A. J. (2014). Development and initial evaluation of a web-based program to increase parental awareness and monitoring of underage alcohol use: A brief report. Journal of Child \& Adolescent Substance Abuse, 23(2), 109-115. https://doi.org/10.1080/1067828X.2012.750553

Campbell, K. J., Hesketh, K. D., McNaughton, S. A., Ball, K., McCallum, Z., Lynch, J., \& Crawford, D. A. (2016). The extended Infant Feeding, Activity and Nutrition Trial (InFANT Extend) program: A cluster-randomized controlled trial of an early intervention to prevent childhood obesity. BMC Public Health, 16(1), 166. https://doi.org/10.1186/s12889-016-2836-0

Carlson Gielen, A., McKenzie, L., McDonald, E. M., Shields, W. C., Wang, M. C., Cheng, Y. J., ... Walker, A. R. (2007). Using a computer kiosk to promote child safety: Results of a randomized, controlled trial in an urban pediatric emergency department. Pediatrics, 120(2), 330-339.

Chen, J. L., Weiss, S., Heyman, M. B., Cooper, B., \& Lustig, R. H. (2011). The efficacy of the web-based childhood obesity prevention program in Chinese American adolescents (Web ABC Study). Journal of Adolescent Health, 49(2), 148-154. https://doi.org/10.1016/j. jadohealth.2010.11.243

Clarke, S. A., Calam, R., Morawska, A., \& Sanders, M. (2013). Developing web-based Triple $P$ "Positive Parenting Programme" for families of children with asthma. Child: Care, Health and Development, 40(4), 492-497. https://doi.org/10.1111/cch.12073

Cook, F., Seymour, M., Giallo, R., Cann, W., Nicholson, J. M., Green, J., \& Hiscock, H. (2015). Comparison of methods for recruiting and engaging parents in online interventions: Study protocol for the cry baby infant sleep and settling program. BMC Pediatrics, 15, 174. https://doi.org/10.1186/s12887-015-0502-9

Cowden, J., Wilkerson-Amendell, S., Weathers, L., Gonzalez, E., Dinakar, C., Westbrook, D., \& Williams, A. (2015). The talking card: Randomized controlled trial of a novel audio-recording tool for asthma control. Allergy and Asthma Proceedings, 36(5), 86-91.

Curtis, K. E., Lahiri, S., \& Brown, K. E. (2015). Targeting parents for childhood weight management: Development of a theory-driven and user-centered healthy eating app. JMIR mHealth and uHealth, 3(2), e69. https://doi.org/10.2196/mhealth.3857

Cushing, C. C., \& Steele, R. G. (2010). A meta-analytic review of ehealth interventions for pediatric health promoting and maintaining behaviors. Journal of Pediatric Psychology, 35(9), 937-949.

Delamater, A. M., Pulgaron, E. R., Rarback, S., Hernandez, J., Carrillo, A., Christiansen, S., \& Severson, H. H. (2013). Web-based family intervention for overweight children: A pilot study. Childhood Obesity, 9(1), 57-63. https://doi.org/10.1089/chi.2011.0126

Delisle, C., Sandin, S., Forsum, E., Henriksson, H., Trolle-Lagerros, Y., Larsson, C., ... Löf, M. (2015). A web- and mobile phone-based intervention to prevent obesity in 4-year-olds (MINISTOP): A population-based randomized controlled trial. BMC Public Health, 15(1), 95. https://doi.org/10.1186/s12889-015-1444-8

Doherty, F., Calam, R., \& Sanders, M. R. (2013). Positive Parenting Program (Triple P) for families of adolescents with type 1 diabetes: A randomized controlled trial of self-directed teen Triple P. Journal of Pediatric Psychology, 38(8), 846-858.

Domek, G. J., Contreras-Roldan, I. L., O'Leary, S. T., Bull, S., Furniss, A., Kempe, A., \& Asturias, E. J. (2016). SMS text message reminders to improve infant vaccination coverage in Guatemala: A pilot randomized controlled trial. Vaccine, 34(21), 2437-2443. https://doi. org/10.1016/j.vaccine.2016.03.065

Ewing, L. J., Long, K., Rotondi, A., Howe, C., Bill, L., \& Marsland, A. L. (2009). Brief report: A pilot study of a web-based resource for families of children with cancer. Journal of Pediatric Psychology, 34(5), 523529. https://doi.org/10.1093/jpepsy/jsn096

Eysenbach, G. (2001). What is e-health? Journal of Medical Internet Research, 3(2), e20. https://doi. org/10.2196/jmir.3.2.e20

Fang, L., \& Schinke, S. P. (2013). Two-year outcomes of a randomized, family-based substance use prevention trial for Asian American adolescent girls. Psychology of Addictive Behaviors, 27(3), 788-798. https://doi. org/10.1037/a0030925

Fidika, A., Herle, M., Lehmann, C., Weiss, C., Knaevelsrud, C., \& Goldbeck, L. (2015). A web-based psychological support program for caregivers of children with cystic fibrosis: A pilot study. Health and Quality of Life Outcomes, 13, 11. https://doi.org/10.1186/s12955015-0211-y

Field, M. J., \& Grigsby, J. (2002). Telemedicine and remote patient monitoring. Journal of the American Medical Association, 288(4), 423-425.

Fox, S. (2005). Digital divisions. Pew Internet \& American Life Project. Retrieved January 18, 2017, from http:// www.pewinternet.org/2005/10/05/digital-divisions/

Gruver, R. S., Bishop-Gilyard, C. T., Lieberman, A., Gerdes, M., Virudachalam, S., Suh, A. W., ... Fiks, A. (2016). A social media peer group intervention for mothers to prevent obesity and promote healthy growth from 
infancy: Development and pilot trial. JMIR Research Protocols, 5(3), e159.

Hall, C. M., \& Bierman, K. L. (2015). Technology-assisted interventions for parents of young children: Emerging practices, current research, and future directions. Early Childhood Research Quarterly, 33, 21-32.

Harris, M. A., Freeman, K. A., \& Duke, D. C. (2015). Seeing is believing: Using Skype to improve diabetes outcomes in youth. Diabetes Care, 38(8), 1427-1434. https://doi.org/10.2337/dc14-2469

Hoghughi, M. (1998). The importance of parenting in child health. Doctors as well as the government should do more to support parents. BMJ, 316(7144), 1545. https://doi.org/10.1136/bmj.316.7144.1545

Horodynski, M. A., Silk, K., Hsieh, G., Hoffman, A., \& Robson, M. (2015). Tools for teen moms to reduce infant obesity: A randomized clinical trial. BMC Public Health, 15, 1-9. https://doi.org/10.1186/s12889-0151345-x

Jones, D. J. (2014). Future directions in the design, development, and investigation of technology as a service delivery vehicle. Journal of Clinical Child \& Adolescent Psychology, 43(1), 128-142. https://doi. org/10.1080/15374416.2013.859082

Jones, D. J., Forehand, R., Cuellar, J., Kincaid, C., Parent, J., Fenton, N., \& Goodrum, N. (2013). Harnessing innovative technologies to advance children's mental health: Behavioral parent training as an example. Clinical Psychology Review, 33(2), 241-252. https:// doi.org/10.1016/j.cpr.2012.11.003

Kahana, S., Drotar, D., \& Frazier, T. (2008). Meta-analysis of psychological interventions to promote adherence to treatment in pediatric chronic health conditions. Journal of Pediatric Psychology, 33(6), 590-611. https://doi.org/10.1093/jpepsy/jsm128

Knapp, C., Madden, V., Wang, H., Sloyer, P., \& Shenkman, E. (2011). Internet use and eHealth literacy of lowincome parents whose children have special health care needs. Journal of Medical Internet Research, 13(3), 1-13. https://doi.org/10.2196/jmir.1697

Kohl, P., Schurer, J., \& Bellamy, J. (2009). The state of parent training: Program offerings and empirical support. Families in Society: The Journal of Contemporary Social Services, 90(3), 248-254.

Levac, D., Colquhoun, H., \& O’Brien, K. K. (2010). Scoping studies: Advancing the methodology. Implementation Science, 5, 69. https://doi.org/10.1186/1748-59085-69

Levy, R. L., Langer, S. L., Walker, L. S., Romano, J. M., Christie, D. L., Youssef, N., ... Whitehead, W. E. (2010). Cognitive-behavioral therapy for children with functional abdominal pain and their parents
Gastroenterology, 105(4), 946-956. https://doi. org/10.1038/ajg.2010.106

MacDonell, K. W., \& Prinz, R. J. (2016). A review of technology-based youth and family-focused interventions. Clinical Child and Family Psychology Review, 1-16. https://doi.org/10.1007/s10567-0160218-x

Maddison, R., Marsh, S., Foley, L., Epstein, L. H., Olds, T., Dewes, O., ... Mhurchu, C. N. (2014). Screentime weight-loss intervention targeting children at home (switch): A randomized controlled trial. The International Journal of Behavioral Nutrition and Physical Activity, 11(1), 111. https://doi.org/10.1186/ s12966-014-0111-2

Madge, C., \& O'Connor, H. (2006). Parenting gone wired: Empowerment of new mothers on the internet? Social \& Cultural Geography, 7(2), 199-220. https://doi. org/10.1080/14649360600600528

Martin, S., Roderick, M. C., Lockridge, R., ToledoTamula, M. A., Baldwin, A., Knight, P., \& Wolters, P. (2016). Feasibility and preliminary efficacy of an internet support group for parents of a child with neurofibromatosis type 1: A pilot study. Journal of Genetic Counseling, 1-10. https://doi.org/10.1007/ s10897-016-0031-1

Mays, N., Roberts, E., \& Popay, J. (2001). Synthesising research evidence. In N. Fulop, P. Allen, A. Clarke, \& N. Black (Eds.), Studying the organisation and delivery of health services: Research methods (pp.188-220). London: Routledge.

Merkel, R. M., \& Wright, T. (2012). Parental self-efficacy and online support among parents of children diagnosed with type 1 diabetes mellitus. Pediatric Nursing, 38(6), 303-308. Retrieved from December 17, 2016, from http://www.ncbi.nlm.nih.gov/ pubmed/23362628

Militello, L., Melnyk, B. M., Hekler, E. B., Small, L., \& Jacobson, D. (2016). Automated behavioral text messaging and face-to-face intervention for parents of overweight or obese preschool children: Results from a pilot study. JMIR mHealth and uHealth, 4(1), e21. https://doi.org/10.2196/mhealth.4398

Nezami, B. T., Lytle, L. A., \& Tate, D. F. (2016). $A$ randomized trial to reduce sugar-sweetened beverage and juice intake in preschool-aged children: Description of the Smart Moms intervention trial. BMC Public Health, 16(1), 837. https://doi.org/10.1186/ s12889-016-3533-8

Nieto, R., Hernández, E., Boixadós, M., Huguet, A., Beneitez, I., \& McGrath, P. (2015). Testing the feasibility of DARWeb: An online intervention for children with functional abdominal pain and their parents. The Clinical Journal of Pain, 31(6), 493-503. https://doi. org/10.1097/AJP.0000000000000199 
Nkoy, F. L., Stone, B. L., Fassl, B. A., Koopmeiners, K., Halbern, S., Kim, E. H., ... Maloney, C. G. (2012). Development of a novel tool for engaging children and parents in asthma self-management. AMIA Annual Symposium Proceedings, 2012, 663-672.

O'Connor, A., Bennett, C., Stacey, D., Barry, M., Col, N., Eden, K., ... Rovner, D. (2009). Decision aids for people facing health treatment or screening decisions. The Cochrane Database of Systematic Review, 3, CD001431. https://doi.org/10.1002/14651858. CD001431.pub2

Pagliari, C., Sloan, D., Gregor, P., Sullivan, F., Detmer, D., Kahan, J. P., ... MacGillivray, S. (2005). What is eHealth (4): A scoping exercise to map the field. Journal of Medical Internet Research, 7(1), 1-20. https://doi. org/10.2196/jmir.7.1.e9

Palermo, T. M., Law, E. F., Fales, J., Bromberg, M., JessenFiddick, T., \& Gabrielle, T. (2016). Internet-delivered cognitive-behavioral treatment for adolescents with chronic pain and their parents: A randomized controlled multicenter trial. Pain, 157(1), 174-185.

Palermo, T. M., Wilson, A. C., Peters, M., Lewandowski, A., \& Somhegyi, H. (2009). Randomized controlled trial of an internet delivered family cognitive behavioral therapy intervention for children and adolescents with chronic pain. Pain, 146(1-2), 205-213. https:// doi.org/10.1016/j.pain.2009.07.034

Ritterband, L. M., \& Palermo, T. M. (2009). Introduction to the special issue: eHealth in pediatric psychology. Journal of Pediatric Psychology, 34(5), 453-456. https://doi.org/10.1093/jpepsy/jsp008

Seeber, L., Conrad, T., Hoppe, C., Obermeier, P., Chen, X., Karsch, K., ... Rath, B. (2017). Educating parents about the vaccination status of their children: A usercentered mobile application. Preventive Medicine Reports, 5, 241-250. https://doi.org/10.1016/j. pmedr.2017.01.002
Stark, L. J., Opipari-Arrigan, L., Filigno, S. S., Simon, S. L., Leonard, A., Mogayzel, P. J., ... Powers, S. W. (2015). Web-based intervention for nutritional management in cystic fibrosis: Development, usability, and pilot trial. Journal of Pediatric Psychology, 41(5), 1-12. https:// doi.org/10.1093/jpepsy/jsv108

Starling, R., Nodulman, J. A., Kong, A. S., Wheeler, C., Buller, D. B., \& Woodall, W. G. (2014). Beta-test results for an HPV information web site: GoHealthyGirls. org - Increasing HPV vaccine uptake in the United States. Journal of Consumer Health on the Internet, 18(3), 226-237.

Stewart, M., Letourneau, N., Masuda, J. R., Anderson, S., \& McGhan, S. (2011). Online solutions to support needs and preferences of parents of children with asthma and allergies. Journal of Family Nursing, 17(3), 357379. https://doi.org/10.1177/1074840711415416

Stinson, J., McGrath, P., Hodnett, E., Feldman, B., Duffy, C., Huber, A., ... White, M. (2010). An internet-based self-management program with telephone support for adolescents with arthritis: A pilot randomized controlled trial. The Journal of Rheumatology, 37(9), 1944-1952.

Wantland, D. J., Portillo, C. J., Holzemer, W. L., Slaughter, R., \& McGhee, E. M. (2004). The effectiveness of web-based vs. non-web-based interventions: A metaanalysis of behavioral change outcomes. Journal of Medical Internet Research, 6(4), e40. https://doi. org/10.2196/jmir.6.4.e40

Whyte, K. L., \& Hunter, I. (2008). Internet access, utilisation and perception by parents. Archives of Disease in Childhood, 93(5), 448-449.

Received: March 6, 2017

Approved: March 23, 2017 
